\title{
A stress fracture of the base of the acromion: a case report
}

\author{
Eduardo Angeli Malavolta, Jorge Henrique Assunção*, Edwin Eiji Sunada, Mauro Emilio Conforto Gracitelli \\ and Arnaldo Amado Ferreira Neto
}

\begin{abstract}
Background: Stress fractures of the base of the acromion are rare and tend to progress well when conservatively treated. The need for surgery due to this type of fracture has only been reported in two case reports.

Case presentation: A 39-year-old patient, manual laborer, with a stress fracture at the base of the acromion that required surgical treatment due to persistent symptoms and consolidation failure.

Conclusion: We described a new mechanism of injury for stress fractures of the base of the acromion. After the failure of conservative treatment, the patient exhibited good results with osteosynthesis with a plate and screws, with no need for a bone graft.
\end{abstract}

Keywords: Scapula, Fractures, Stress, Fracture fixation, Pseudarthrosis

\section{Background}

Acromion fractures of the scapula are rare and have been given little consideration since they have traditionally been managed nonoperatively, often with favorable outcomes[1]. Indications for operative management include symptomatic nonunion, displaced fractures, or acromion fractures associated with other lesions of the superior shoulder suspensory complex[1,2]. Fractures may be caused by a direct lateral blow to the shoulder, avulsed from indirect forces to the deltoid muscle, or the result of overuse injuries[1].

Stress fractures of the base of the acromion[3-10] are very rare and are usually successfully treated using conservative procedures $[4,5,7,8]$. The need for surgery due to this type of fracture has only been reported in two case reports $[9,10]$. We report a case of a patient with a stress fracture of the base of the acromion who underwent surgery because of a symptomatic nonunion.

\section{Case presentation}

A 39-year-old right hand dominant male sought our services with a history of eight months of pain in the posterior region of the left shoulder, with no history of acute

\footnotetext{
* Correspondence: drjorgeassuncao@gmail.com

Shoulder and Elbow Group, Institute of Orthopedics and Traumatology, School of Medicine, University of São Paulo (Universidade de São Paulo; USP), Address: Rua Ovidio Pires de Campos, 333, São Paulo, SP, Brazil
}

trauma. The patient stated that the pain began after starting a job where he carried sandbags of approximately $25 \mathrm{~kg}$ on the affected shoulder. The pain began after two months on the new job and progressively worsened with time. The pain was worse with exertion. The pain was partially relieved with rest and the use of non-steroidal antiinflammatory drugs. At the time of his first appointment, the patient was unable to work, and he did not report any comorbidity.

Physical examination of the left shoulder revealed no gross deformity. On palpation, the patient reported pain over the scapular spine, approximately $5 \mathrm{~cm}$ medial to the lateral border of the acromion. The passive range of motion was normal, and active forward elevation, abduction and external rotation were limited to $130^{\circ}, 90^{\circ}$ and $30^{\circ}$, respectively. The patient exhibited pain and decreased strength on the Jobe and infraspinatus tests as well as negative signs for a superior labrum anterior and posterior (SLAP) lesion and acromioclavicular arthrosis. The functional assessment scored 10 points on the University of California at Los Angeles (UCLA) Shoulder Rating scale and 7 points on the visual analog scale.

The initial radiographs revealed a transverse fracture of the base of the acromion on the spinoglenoid notch without deviation (Figure 1). A non-surgical treatment with analgesics, rest, absence from work, and physical therapy (analgesia, stretching, and strengthening) was 


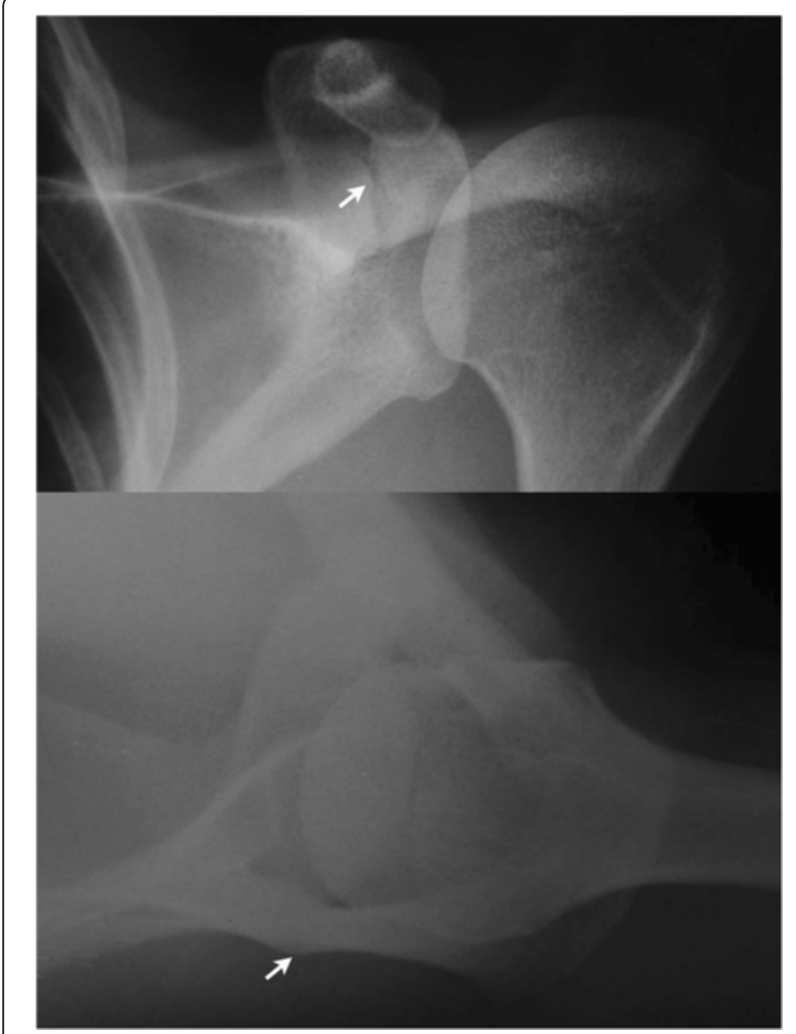

Figure 1 Preoperative radiographs. Radiographs in the anteroposterior and axillary views demonstrating (arrows) the transverse fracture and the lack of deviation of the base of the acromion.

used for four months, with no clinical improvement. New imaging exams (radiography, computed tomography $(\mathrm{CT})$, and magnetic resonance imaging (MRI)) revealed the absence of consolidation (Figures 2 and 3). Thus, after 4 months of conservative treatment and 1 year after the onset of symptoms, surgical treatment was recommended.

The patient was placed in the prone position, and a $10 \mathrm{~cm}$ incision was made along the scapular spine towards the lateral edge of the acromion. The trapeziusdeltoid fascia was opened towards the spine. The deltoid and trapezius muscles were detached, exposing the pseudarthrosis focus, with hypertrophic callus. A partial resection of the hypertrophic callus was performed, and the scapular spine was anatomically reduced. The osteosynthesis was performed with a 6-hole $3.5-\mathrm{mm}$ locking compression plate (LCP) with 3 screws locked proximally and 2 distal screws, 1 of them locked and 1 cortical screw placed eccentrically, resulting in an interfragmentary compression of $1 \mathrm{~mm}$ (Figure 4). The lateral fixation with 3 screws was not possible due to the location of the fracture. No bone graft was used, and the incision was closed in layers, reinserting the muscles using transosseous sutures.

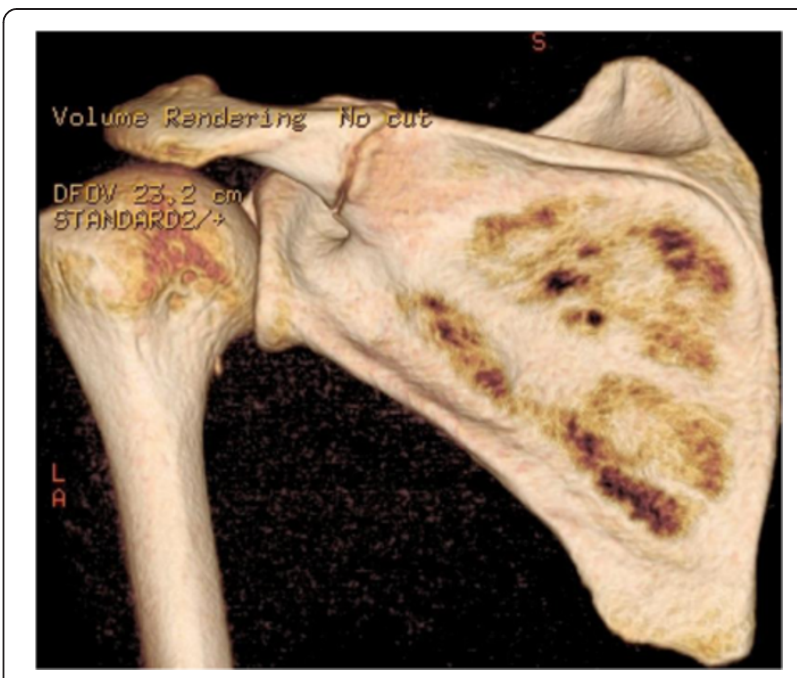

Figure 2 Preoperative CT. Posterior view of the left shoulder on CT with 3-dimensional reconstruction performed after 4 months of conservative treatment. An absence of consolidation of the fracture at the base of the acromion on the spinoglenoid notch can be observed.

The operated limb was immobilized with an arm sling for 6 weeks, and the mobilization of the hand, wrist, and elbow was performed beginning on the 1st postoperative day. Passive shoulder movements were started at 3 weeks, free active movements at 6 weeks and resistance movements at 8 weeks. After 4 postoperative months, the patient had recovered full range of motion. The radiograph (Figure 5) and the CT performed at 5 postoperative months (Figure 6) revealed the healed

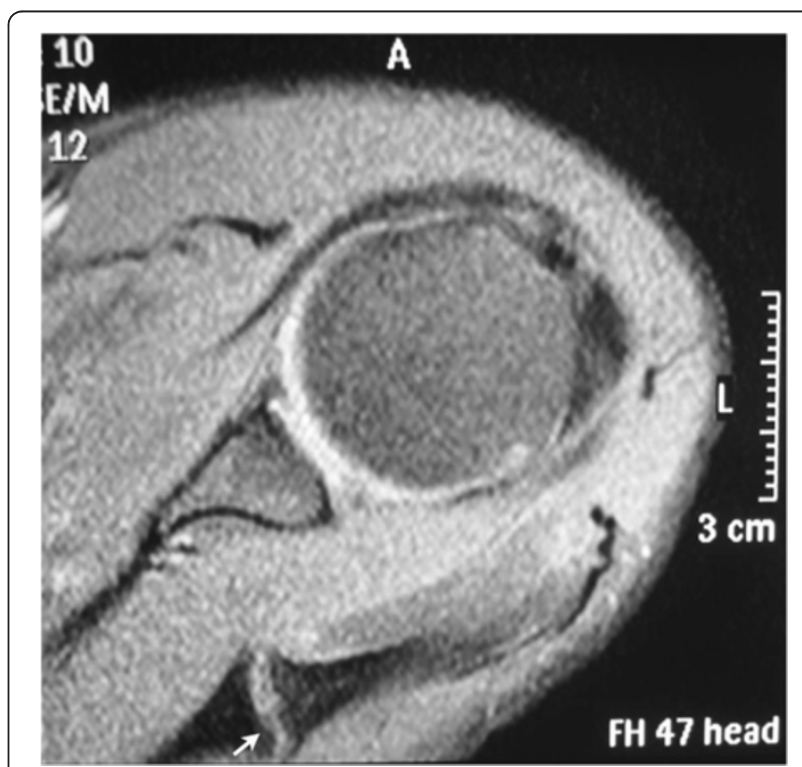

Figure 3 Preoperative magnetic resonance imaging (MRI).

An axial section of the T2-weighted MRI demonstrating a hypertrophic pseudarthrosis of the fracture of the base of the acromion (arrow). 


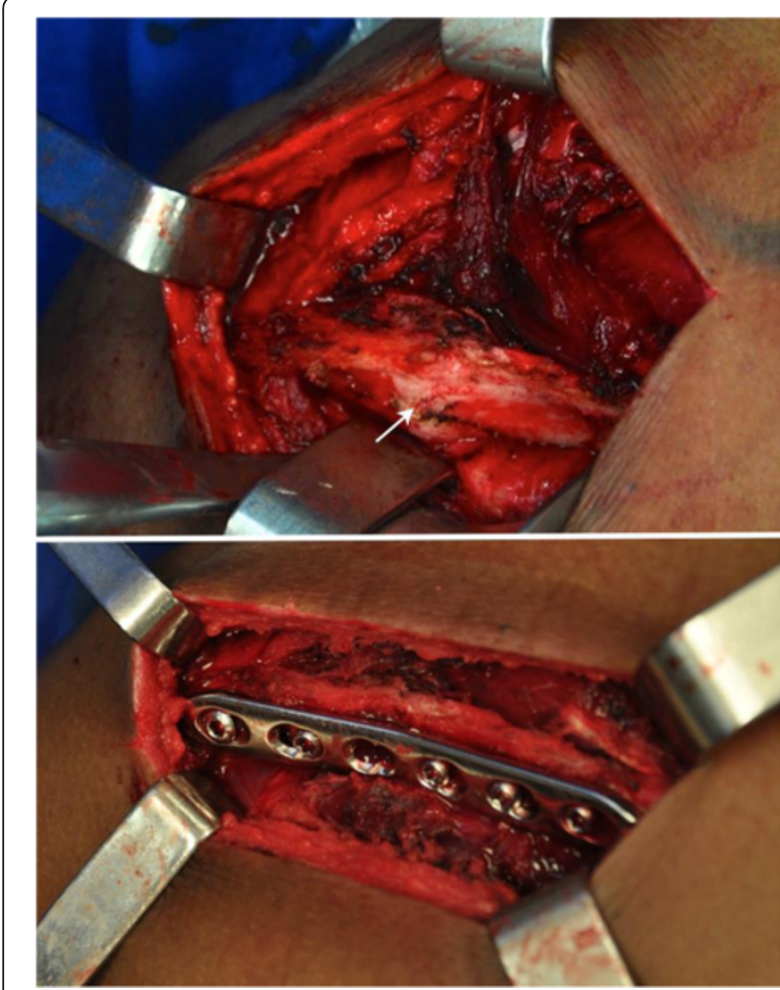

Figure 4 Intraoperative images. The arrow indicates the location of the pseudarthrosis focus after partial resection of the hypertrophic callus and after the scapular spine was placed in the normal position. Below, the fracture was fixed with a $3.5 \mathrm{~mm}$ LCP with 3 screws proximal to the focus and 2 screws distal to the focus.

fracture. After 6 months, the patient rarely reported mild pain and returned to his work. The UCLA scale was 33 at 6 months of follow-up and 35 at 12 months. The maximum UCLA score is 35 points. The patient recovered full painless range of motion and normal strenght.

\section{Conclusion}

Stress fractures of the base of the acromion are rare [3-10], and the literature only describes case reports. Possible causes for the occurrence of these fractures are rotator cuff arthropathy $[3,6]$, history of reverse arthroplasty [10], manual lifting work [5], golfing [4,7], football [8], and artistic gymnastics [9]. Our report describes the act of repeatedly carrying weight on the shoulder as a new mechanism of injury for this condition.

Conservative treatment is considered a viable treatment option in most reports $[3-7,10]$. In patients with low functional demands, even when there is no consolidation, this treatment can be effective in improving symptoms [6]. However, osteosynthesis is necessary when the symptoms persist $[9,10]$. Our patient had been complaining for 12 months at the time of surgery, with no potential for consolidation according to our assessment.

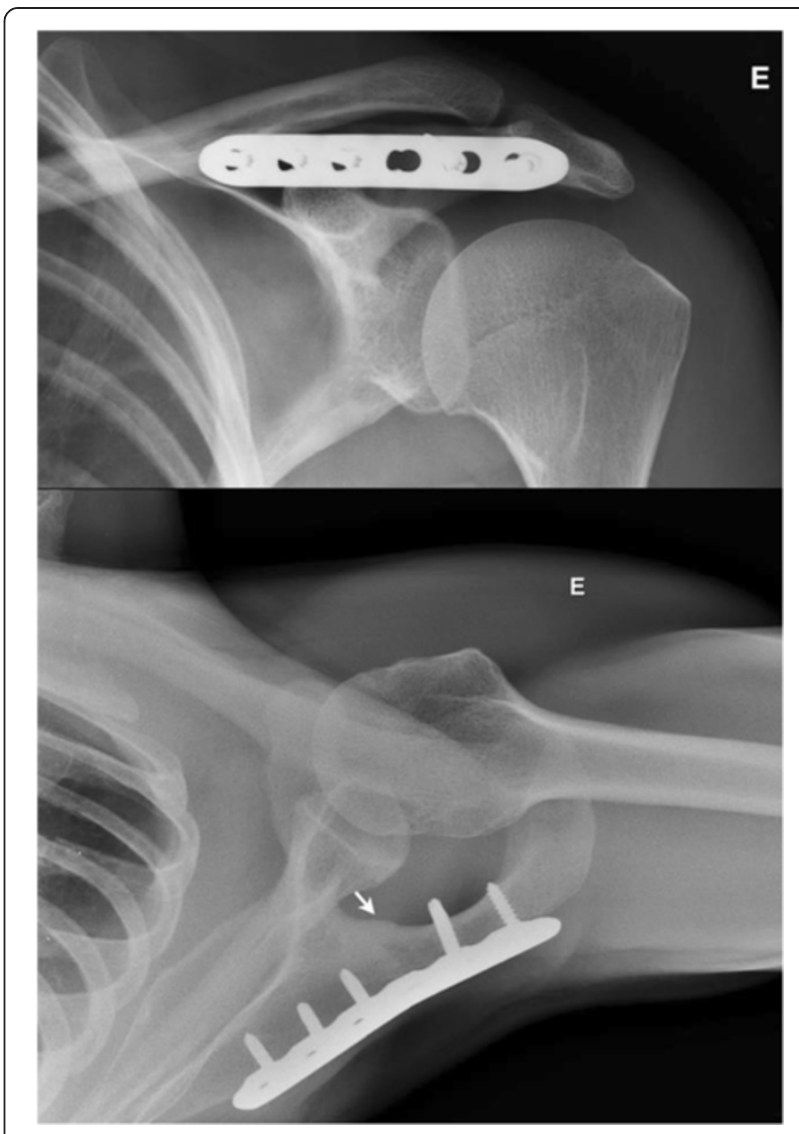

Figure 5 Postoperative radiographs. Postoperative anteroposterior and axillary radiographs demonstrating fracture consolidation (arrow).

Similar to Wahlquist et al. [10], we believe that fractures of the base of the acromion exhibit different characteristics than fractures of the acromion and the spine. Due to the insertion of the deltoid and trapezius muscles, these fractures exhibit a greater tendency towards

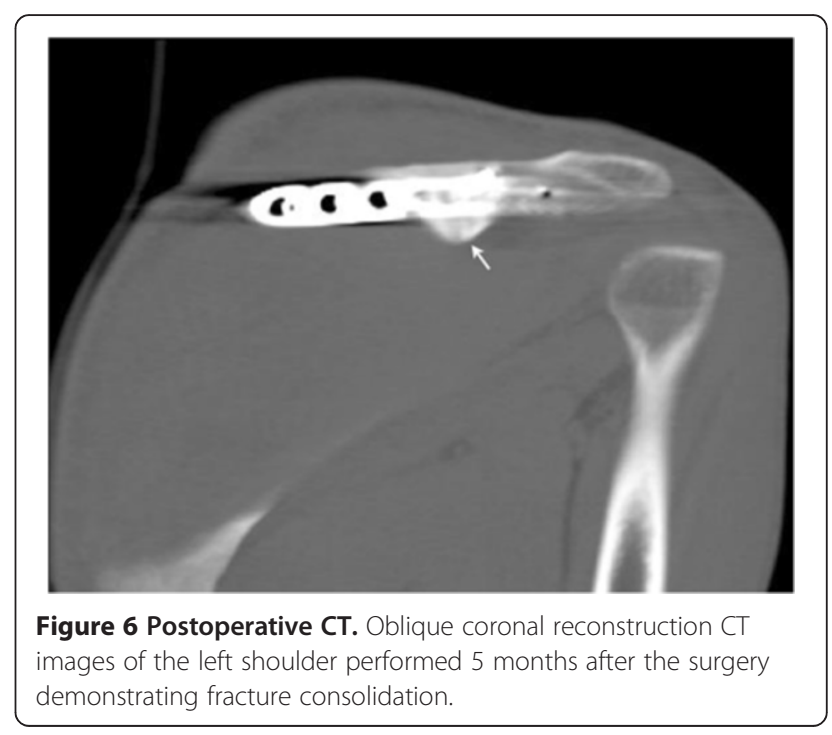


instability and may justify a change in muscle function with functional impairment and the increased risk of pseudarthrosis.

The surgical techniques described for the osteosynthesis of these fractures involve plates and screws [10] or the use of tension-band wiring using autologous [9] or synthetic bone grafts [10]. Our report differs from previous reports in that we did not use a bone graft. We believe that the reason for nonunion of the fracture was the lack of stability and not a vascularization failure. There was no bone loss and fracture was a hypertrophic nonunion.

It is noteworthy that there is an inconsistency in the nomenclature for this type of fracture in the literature. Even when occurring in the same anatomical region, next to the spinoglenoid notch, these fractures are treated as fractures of the acromion [3,5,7,9], of the base of the acromion $[6,8,10]$, or of the spine [11]. The previous reports could be used the classification of Ogawa and Naniwa [12]. These authors advocate that acromion fractures should be classified into two types in terms of clinical consideration: type I fractures, comprising those of the anatomic acromion and the extremely lateral scapular spine, and type II fractures, located in the more medial spine and descending to the spinoglenoidal notch. Our patient had a type II fracture.

Ultimately, we described a new mechanism of injury for stress fractures of the base of the acromion. After the failure of conservative treatment, the patient exhibited good results with osteosynthesis with a plate and screws, with no need for a bone graft.

\section{Consent}

Written informed consent was obtained from the patient for publication of this case report and any accompanying images. A copy of the written consent is available for review by the Editor of this journal.

\section{Abbreviations}

SLAP: Superior Labral Anterior and Posterior; UCLA: University of California at Los Angeles; CT: Computed tomography; MRI: Magnetic resonance imaging; LCP: Locking compression plate.

\section{Competing interests}

We have no competing interests.

\section{Authors' contributions}

EAM, EES and MECG wrote the manuscript, prepared the pictures and participated as a surgeon. EAM, JHA and AAFN contributed to the conception and design, and performed critical revision of the manuscript. All authors read and approved the final manuscript.

\section{Authors' information}

EAM, EES, MECG and JHA are assistant physicians at Shoulder and Elbow Group of the University of São Paulo. AAFN is MD-PhD, Chair of the Shoulder and Elbow Group.

Received: 29 July 2013 Accepted: 4 September 2014

Published: 12 September 2014

\section{References}

1. Anavian J, Wijdicks CA, Schroder LK, Vang S, Cole PA: Surgery for scapula process fractures. Good outcome in 26 patients. Acta Orthop 2009, 80:344-350.

2. Hill BW, Anavian J, Jacobson AR, Cole PA: Surgical management of isolated acromion fractures: Technical tricks and clinical experience. J Orthop Trauma 2014, 28:107-113.

3. Dennis D, Ferlic D, Clayton M: Acromial stress fractures associated with cuff-tear arthropathy. J Bone Joint Surg Am 1986, 68:937-940.

4. Hall R, Calvert P: Stress fracture of the acromion: an unusual mechanism and review of the literature. J Bone Joint Surg (Br) 1994, 77:153-154.

5. Rask M, Steinberg L: Fracture of the acromion caused by muscle forces. J Bone Joint Surg Am 1978, 60:1146-1147.

6. Roy N, Smith M, Jacobs L: Stress fracture of base of the acromion. Ann Rheum Dis 2002, 61:944-945.

7. Taneja AK, Negromonte FP, Skaf A: Stress injury of the acromion: case report and literature review. Eur J Orthop Surg Traumatol 2013, 23:S189-S192.

8. Ward WG, Bergfeld JA, Carson WG: Stress fracture of the base of the acromial process. Am J Sports Med 1994, 22:146-147.

9. Warner JJ, Port J: Stress fracture of the acromion. J Shoulder Elbow Surg 1994, 3:262-265.

10. Wahlquist TC, Hunt AF, Braman JP: Acromial base fractures after reverse total shoulder arthroplasty: report of five cases. J Shoulder Elbow Surg 2011, 20:1178-1183.

11. As-Sultany M, Tambe A, Clark D: Nonunion of a scapular spine fracture: case report and management with open reduction, internal fixation, and bone graft. Int J Shoulder Surg 2008, 2:64-67.

12. Ogawa K, Naniwa T: Fractures of the acromion and the lateral scapular spine. J Shoulder Elbow Surg 1997, 6:544-548.

doi:10.1186/1471-2474-15-302

Cite this article as: Malavolta et al:: A stress fracture of the base of the acromion: a case report. BMC Musculoskeletal Disorders 2014 15:302.

\section{Submit your next manuscript to BioMed Central and take full advantage of:}

- Convenient online submission

- Thorough peer review

- No space constraints or color figure charges

- Immediate publication on acceptance

- Inclusion in PubMed, CAS, Scopus and Google Scholar

- Research which is freely available for redistribution 